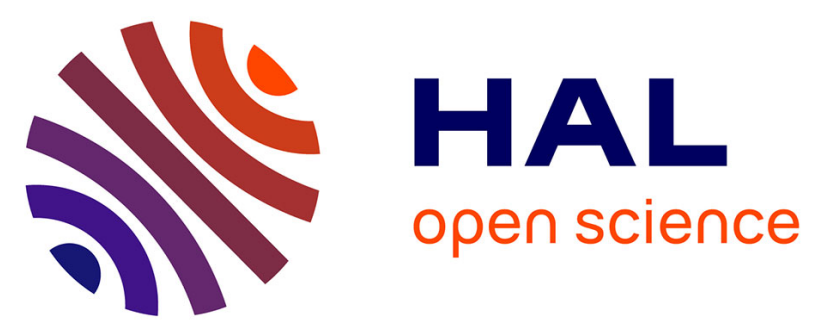

\title{
Prospective evaluation of the Amplidiag® CarbaR+VRE assay for direct screening of carbapenemase producing gram-negative bacilli from rectal swabs
}

\author{
Safia Nadji, Olivier Gaillot, Christophe Hallaert, Sophian Messaadi, \\ Nourredine Loukili, Thierry Naas, Nadine Lemaître
}

\section{To cite this version:}

Safia Nadji, Olivier Gaillot, Christophe Hallaert, Sophian Messaadi, Nourredine Loukili, et al.. Prospective evaluation of the Amplidiag® CarbaR+VRE assay for direct screening of carbapenemase producing gram-negative bacilli from rectal swabs. Diagnostic Microbiology and Infectious Disease, 2019, 95, pp.114890 -. 10.1016/j.diagmicrobio.2019.114890 . hal-03488787

\section{HAL Id: hal-03488787 https://hal.science/hal-03488787}

Submitted on 21 Dec 2021

HAL is a multi-disciplinary open access archive for the deposit and dissemination of scientific research documents, whether they are published or not. The documents may come from teaching and research institutions in France or abroad, or from public or private research centers.
L'archive ouverte pluridisciplinaire HAL, est destinée au dépôt et à la diffusion de documents scientifiques de niveau recherche, publiés ou non, émanant des établissements d'enseignement et de recherche français ou étrangers, des laboratoires publics ou privés.

\section{(ㅇ)(1) $\$$}

Distributed under a Creative Commons Attribution - NonCommerciall 4.0 International 
1 Prospective evaluation of the Amplidiag ${ }^{\circledR}$ CarbaR+VRE assay for direct screening of

2 carbapenemase producing Gram-negative bacilli from rectal swabs

3

4 Safia Nadji ${ }^{\mathrm{a}}$, Olivier Gaillot ${ }^{\mathrm{a}, \mathrm{b}}$, Christophe Hallaert $^{\mathrm{a}}$, Sophian Messaadi ${ }^{\mathrm{a}}$ Nourredine Loukili ${ }^{\mathrm{c}}$,

$5 \quad$ Thierry Naas ${ }^{\mathrm{d}, \mathrm{e}}$, Nadine Lemaître ${ }^{\mathrm{a}, \mathrm{b} *}$

6

$7 \quad$ a Service de Bactériologie-Hygiène, CHU Lille, Lille, France

8 b CNRS, INSERM, CHU Lille, U1019 - UMR 8204, Center for Infection and Immunity,

$9 \quad$ Lille, France

${ }^{c}$ Unité de Lutte contre les Infections Nosocomiales, CHU Lille, Lille, France

d EA7361 "Structure, dynamic, function and expression of broad spectrum $\beta$-lactamases", Paris-Sud University, Faculty of Medicine, Service de Bactériologie-Hygiène, Hopital Bicêtre, Assistance Publique - Hôpitaux de Paris, Le Kremlin-Bicêtre, France

e French National Reference Center for Antibiotic Resistance: Carbapenemen-resistant Enterobacteriaceae, Bicêtre Hospital, Le Kremlin-Bicêtre, France

Keywords: carbapenemase, rectal swab, real-time PCR, Enterobacteriaceae, Amplidiag ${ }^{\circledR}$ CarbaR+VRE assay, Amplidiag ${ }^{\circledR}$ Easy platform

Running title: Detecting carbapenemases with real-time PCR

Words count: Abstract $=146$

main text $=3177$

*Address correspondence to Nadine Lemaître, nadine.lemaitre@chru-lille.fr

Service de Bactériologie-Hygiène, Centre de Biologie Pathologie, CHU Lille, Lille, France: +33 3204456 92; Fax: +33 20444895 


\section{Abstract}

This prospective study evaluated the ability of the qPCR Amplidiag ${ }^{\circledR} \mathrm{CarbaR}+\mathrm{VRE}$ assay to detect Carbapenemase-producing Gram-negative bacilli (CP-GNB) directly on 1,830 rectal swabs extracted using the fully automated platform Amplidiag ${ }^{\circledR}$ Easy instrument.

The Amplidiag ${ }^{\circledR}$ CarbaR+VRE assay gave a positive signal for 94 rectal swabs, whereas only 70 grew with CP-GNB on chromogenic media including 4 VIM-producing $P$. aeruginosa, 8 OXA-23-producing $A$. baumannii and 58 carbapenemase-producing Enterobacteriaceae. All the CP-GNB culture positive were detected by the Amplidiag ${ }^{\circledR}$ CarbaR+VRE assay. Twenty-four qPCR positive and culture negative samples were further investigated using targeted PCRs and subsequent DNA sequencing. Seventeen and seven of these were positive and negative with PCR/DNA sequencing, respectively. Taken together, the Amplidiag ${ }^{\circledR}$ CarbaR+VRE could detect carbapenemases directly from rectal swabs in 3h30 using a fully automated platform and showed high biological performances (sensitivity, specificity, negative and positive predictive values were 100, 98.6, 100 and 74.5\%, respectively). 


\section{Introduction}

Over the last decade, increasing resistance to carbapenems, the favored last resort drugs for treating multidrug resistant (MDR) Gram-negative bacterial (GNB) infections, is a serious threat to global health. Resistance is largely attributed to carbapenemases that are capable of hydrolyzing most $\beta$-lactams (including carbapenems) and are carried by diverse transferable mobile genetic elements (plasmids, transposons and integrons) $(1,2)$. These elements usually carry multiple additional resistance genes that confer resistance to most non$\beta$-lactam antibiotics and therefore greatly reduce treatment options. Consequently, infections caused by carbapenemase-producing Gram-negative bacilli (CP-GNB) are difficult to treat, associated with high mortality rates and costly to healthcare facilities (3).

OXA-48, NDM, KPC, IMP and VIM are the most common carbapenemases among carbapenemase-producing Enterobacteriaceae (CPE) with great geographic differences in the prevalence $(4,5)$. Currently, OXA-48 and its variants (OXA-48-like) are the most clinicallyrelevant carbapenemases in some Western European countries (France, Belgium and Spain) and are frequently found in Klebsiella pneumoniae, Escherichia coli and Enterobacter spp. (5).

Many hospital outbreaks of CP-GNB have been reported in several countries (5). Consequently, guidelines for the prevention and control of CP-GNB based on early active screening of asymptomatic carriers at hospital admission have been implemented in many settings (6-8). The early identification of colonized patients with CP-GNB combined with quarantine of these patients is the cornerstone of the prevention of outbreaks with CP-GNB ("search and isolate" strategy). The current process for detecting CP-GNB using rectal swabs is usually performed with chromogenic culture media containing antibiotics. However, culture-based methods for screening are time-consuming and require at least $18 \mathrm{~h}$ incubation to obtain growing bacteria, and additional time (going from a few minutes to several hours) to 
confirm the presence of a CP-GNB. Moreover, some of these media are unable to detect OXA-48 and its variants because of low level hydrolytic activity against carbapenems (9-12). Therefore, molecular methods using multiplex real-time PCR (qPCR) assays have been recently developed to rapidly detect the most frequent carbapenemase genes from rectal swabs with shorter turnaround times (13-15). The aim of this study was to investigate the performance of the qPCR Amplidiag ${ }^{\circledR}$ CarbaR+VRE assay (Mobidiag, Paris, France), designed to simultaneously detect the most prevalent carbapenemases in Enterobacteriaceae (OXA-48-, NDM-, KPC-, VIM- and IMP-likes) and in A. baumannii (OXA-23, OXA-40, OXA-58, and OXA-51 with an upstream inserted ISAbaI), vanA and vanB genes directly from rectal swabs and, to assess the workability of this qPCR screening method in the context of a routine diagnostic laboratory that weekly processes around 400 rectal swabs. We focused the evaluation of the Amplidiag ${ }^{\circledR}$ CarbaR+VRE assay on the detection of the most common carbapenemases among GNB because Lille hospital is particularly impacted by CP-GNB outbreaks especially with CPE outbreaks while it is not the case for vancomycin-resistant enterococci (VRE). Consequently, the systematic screening for fecal carriage of VRE is not implemented in our hospital.

\section{Material and methods}

\subsection{Settings and surveillance samples}

This prospective study was conducted between November 2017 and February 2018 at the teaching hospital of Lille (2,965 beds). During this 4-month period, a total of 1,830 consecutive rectal swabs from 1,301 patients were collected according to hospital's CP-GNB standard infection control program. A mean of 1.40 rectal swab (range 1-7) were obtained per patient (one from 955 patients, 2 from 219 patients, 3 from 78 patients, 4 from 28 patients, 5 from 7 patients, 6 from 4 patients and 7 from 3 patients). Briefly, active screening for rectal 
carriage of carbapenem-resistant organisms was performed among patients i) admitted to high-risk facilities for acquisition of such organisms (medical and surgical intensive care, burn, hematology and long-term care units), ii) admitted to healthcare facilities with known CP-GNB outbreak and iii) transferred from another hospital or from countries with high CPGNB prevalence or identified as CP-GNB contact or with past history of CP-GNB colonization (6). These patients were preemptively isolated with additional contact precautions (staff wear gowns, single-room isolation, dedicated equipment) while waiting the fecal swab screening results. Sample collection was performed as follows: a single rectal swab in Amies medium (Transwab ${ }^{\circledR}$, Sigma, Fallavier, France) were obtained on admission and then once a week until the patient's discharge. Within $24 \mathrm{~h}$, the samples were directly plated (without pre-enrichment step in brain heart broth) on each side of the chromogenic chromID $^{\circledR}$ CARBA SMART agar medium (bioMérieux ${ }^{\circledR}$, Marcy l'Etoile, France) with the PREVI ${ }^{\circledR}$ Isola automated seeder system (bioMérieux) and analyzed by the multiplex real-time PCR Amplidiag ${ }^{\circledR}$ CarbaR+VRE assay, as recommended by the manufacturer.

\subsection{Culture-based screening for CPE and drug susceptibility testing}

Suspected carbapenem-resistant colonies were identified using MALDI-TOF mass spectrometry (Brüker Biotyper, Wissenbourg, France) and were submitted to susceptibility testing using the automated system Vitek 2 (BioMérieux). MICs of carbapenems were determined with E-tests (BioMérieux) and interpreted according the guidelines of the Committee for Antibiogram of the French Society of Microbiology (CA-SFM) / European Committee on Antimicrobial Susceptibility Testing (EUCAST) and carbapenemase activity was detected by the $\beta$-carba ${ }^{\mathrm{TM}}$ test (BioRad, Marnes la Coquette, France). Specific rapid (15 min.) detection of OXA-48 and related enzymes, KPC and NDM carbapenemases production was carried out using immunochromatographic assay (ICT) Resist-3 O.K.N. K-SeT (Coris 
117 Bioconcept, Gembloux, Belgium) because these 3 carbapenemases are predominant in

118 Enterobacteriaceae isolated from our hospital. The Xpert Carba-R V2 ${ }^{\circledR}$ assay (Cepheid,

119 Maurens Scopont, France) was used for the detection of genes coding for VIM and IMP 120 enzymes or for samples positive for growth on chromID ${ }^{\circledR}$ CARBA SMART medium but 121 negative with ICT assay. Bla OXA-23 gene detection was performed using an in-house PCR 122 directly on colonies of Acinetobacter spp. by using the following in-house designed primers OXA-23F (forward), 5'-TTCTGGTTGTACGGTTCAGCA-3' and OXA-23R (reverse) 5'ATATCCATTGCCCAACCAGTC-3'.

2.3 Direct detection of carbapenemase genes in rectal swabs with Amplidiag ${ }^{\circledR}$ CarbaR $+V R E$ assay

Briefly, on the day of the sample collection, $300 \mu \mathrm{L}$ of Transwab $^{\circledR}$ liquid was suspended in eNat ${ }^{\mathrm{TM}}$ tubes (Copan Italia SpA, Brescia, Italy) and incubated for $30 \mathrm{~min}$ at room temperature. Then, the $\mathrm{eNat}^{\mathrm{TM}}$ tubes were loaded on the fully automated platform Amplidiag $^{\circledR}$ Easy for DNA extraction and PCR plate setup according to the manufacturer's instructions (Mobidiag, Helsinki, Finland). Forty-eight samples could be extracted in 2 hours and subsequently analyzed in one PCR run. The assay panel Amplidiag ${ }^{\circledR}$ CarbaR+VRE

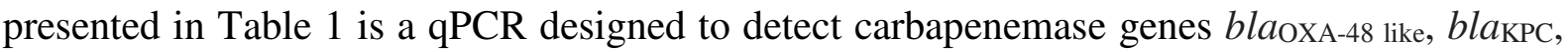
bla $_{\mathrm{NDM}}$, bla $a_{\mathrm{IMP}}$, blaviM as well as undifferentiated Acinetobacter oxacillinases: OXA-23, OXA-40, OXA-58 and OXA-51 with upstream inserted ISAbaI (blaAcOXA), vanA and vanB genes $(16,17)$. Internal amplification control, positive and negative PCR controls are included in each PCR plate to provide assurance that clinical specimens have been successfully amplified. Total run time was $3 \mathrm{~h} 30$ for DNA extraction $(2 \mathrm{~h})$ and for 45 cycles of amplification (1h30) as recommended by the manufacturer. Run files were automatically 
exported from the PCR software to be interpreted by the provided Amplidiag ${ }^{\circledR}$ Analyzer software (Mobidiag).

\subsection{Data analysis}

A qPCR positive result was considered when a $\mathrm{Ct}$ value of $<45$ was detected for at least one carbapenemase gene. True positive results were defined as a positive carbapenemase gene signal on direct qPCR assay if any of the carbapenemase targets were positive and were identical to that gene detected on colonies growing on the selective media. True negative results were defined as a negative carbapenemase gene signal on direct qPCR assay if all of the carbapenemase targets were negative and the selective culture did not grow with CPE. Discrepant results are classified as a result obtained using direct Amplidiag ${ }^{\circledR}$ CarbaR+VRE assay that did not agree with the reference-culture method on the same sample. The corresponding DNAs of discrepant rectal swabs were sent to Mobidiag in Finland for result confirmation. They were reanalyzed by simplex PCR on extracted DNA from specimens with the following PCR cycling parameters $\left(1 \mathrm{~min}\right.$. at $95^{\circ} \mathrm{C}$, followed by 45 cycles of $15 \mathrm{sec}$. at $95^{\circ} \mathrm{C}$ and 1 min. at $60^{\circ} \mathrm{C}$ ). Then, direct DNA sequencing of target genes was performed using the same amplification primer set used in the Amplidiag ${ }^{\circledR}$ CarbaR+VRE assay (Patent $\left.\mathrm{N}^{\circ} \mathrm{EP} 2430188 \mathrm{~B} 1\right)$.

\subsection{Statistical analysis}

Sensitivity, specificity, negative and positive predictive values (NPV and PPV) of Amplidiag ${ }^{\circledR}$ CarbaR+ VRE assay were calculated for all samples tested by using the presence of CP-GNB on chromogenic culture as the reference standard. We applied the Youden index [(sensitivity + specificity)-1] to determine an optimal cycle threshold $(\mathrm{Ct})$ cut-off of qPCR for 
discriminating the true positives (18). The difference in mean $\mathrm{Ct}$ between true- and falsepositive samples was analyzed using Student's t-test.

\section{Results}

\subsection{Comparison of Amplidiag® CarbaR+VRE assay with culture}

During the four-month study period, the presence of CP-GNB and carbapenemase genes were detected in $70(3.8 \%)$ and $94(5.1 \%)$ of the 1,830 rectal swabs using referenceculture method and qPCR Amplidiag ${ }^{\circledR}$ CarbaR+VRE, respectively (Figure 1). It should be noted that 4 and 8 rectal swabs grew with VIM-producing Pseudomonas aeruginosa and OXA-23-producing Acinetobacter baumannii, respectively on ChromID ${ }^{\circledR}$ CARBA SMART medium. Among the 58 rectal swabs culture positive with CPE, 19 yielded more than one microorganism, especially among the OXA-48 producers (Table 2). K. pneumoniae was the most frequently $(\mathrm{n}=34)$ isolated Enterobacteriaceae followed by Escherichia coli $(\mathrm{n}=17)$ and Enterobacter cloacae $(\mathrm{n}=9)$. Here, the most prevalent carbapenemase among Enterobacteriaceae screened by the both methods were OXA-48, followed by KPC and NDM (Tables 2 and 3). Metallo-ß-lactamases VIM and IMP were not detected in Enterobacteriaceae isolates grown on CARBA SMART medium (Tables 2 and 3). With a Ct cut-off value of $<45$, the qPCR Amplidiag ${ }^{\circledR}$ CarbaR+VRE detected all the 70 carbapenemase culture positive samples (sensitivity, 100\%).

Twenty-four samples were negative by culture but yielded a positive qPCR result for at least one targeted carbapenemase gene: $\operatorname{blaXA}_{\mathrm{OX}-48}(\mathrm{n}=13), \operatorname{bla}_{\mathrm{KPC}}(\mathrm{n}=1), \operatorname{bla}_{\mathrm{NDM}}(\mathrm{n}=3)$, bla $_{\mathrm{VIM}}(\mathrm{n}=5)$ and bla $_{\mathrm{IMP}}(\mathrm{n}=2)$ and were classified as false positive results (specificity, 98.6\%). The NPV value was excellent (100\%) but the PPV value was lower (74.5\%). Finally, 
concordant results were found in 1,806 (98.6\%) rectal swabs (70 positives and 1,736 negatives).

\subsection{Discrepant results}

The samples corresponding to the 24 discrepant results were reanalyzed by simplex PCR plus DNA sequencing and were reinoculated by manual direct plating of rectal swab on chromogenic medium. The status of these samples was unchanged and the subsequent culture was negative for CPE. Unfortunately, subsequent rectal swabs of the corresponding patients could not be performed because all these patients but one was discharged from hospital. Seventeen of these 24 samples $(71 \%)$ were confirmed positive for a carbapenemase-encoding gene using the simplex PCR followed by DNA sequencing, and thus could correspond to true positives (Table 4). Of these 17 samples, three samples were collected from three patients with a past history of CPE carriage (2 OXA-48 and one NDM producers) and 5 were collected in wards in which outbreaks of OXA-48 producers were ongoing. The 24 qPCR positive and culture negative samples showed a significantly higher $\mathrm{Ct}$ values (mean $\mathrm{Ct}$ of $38.0 \pm$ 4.4) than true-positives (mean $\mathrm{Ct}$ of $28.8 \pm 5.6$ ), $P<0.0001$. The remaining $7 \mathrm{qPCR}$ positive and culture negative samples could not be confirmed using simplex PCR and might indeed correspond to true negatives. $\mathrm{Ct}$ values for these 7 samples were significantly higher to those of 17 samples that could be confirmed by simplex PCR $(41.0 \pm 3.1 v s 36.5 \pm 4.3, P=0.008)$. It is conceivable that these 7 samples were misclassified due to a non-optimal Ct cut-off. A slight decrease of the Ct cut-off value to $\leq 42$ would improve the PPV (74.5\% vs $76.9 \%$ ) while sensitivity, specificity and Youden index (100\%, $98.8 \%$ and 0.99 , respectively) would be very high. Finally, implementation of qPCR allowed the detection of 17 additional samples positive for carbapenemase genes as compared to our culture-based method. 
The implementation of automated qPCR has proven to be well-suited for the routine of our laboratory which weekly processes up to 400 to 500 rectal swabs for rapid screening of CPGNB among high risk patients. Indeed, the Amplidiag ${ }^{\circledR}$ Easy platform automates the nucleic acid extraction and PCR plates set up, enabling 48 samples screening in $3 \mathrm{~h} 30$. The only manual handling is the transfer of the ready PCR plates into the thermocycler. When a first set of extraction was ready to run qPCR, another set of 48 samples could be automatically extracted. In practice, 2 to 3 series of 48 rectal swabs could be processed per day with a time to results of $3 \mathrm{~h} 30$ vs $29 \mathrm{~h}$ for culture-based methods. In addition, the average costs of processing both positive and negative screens was quite similar between culture reference method ( $9 €)$ and Amplidiag ${ }^{\circledR}$ CarbaR+VRE assay $(11 €)$. This cost included both laboratory reagents and staff time to manage rectal swabs sent to laboratory.

\section{Discussion}

Since CP-GNB outbreak situations are recognized in our hospital (mainly OXA-48 producing Enterobacteriaceae), the workload due to active screening of rectal carriage of CP-GNB has significantly increased. Thus, the number of rectal swabs received in our lab has been multiplied five-fold between 2014 and 2017. Even with an automated streaking instrument, plating and reading plates are time-consuming and uses up significant space in our $35^{\circ} \mathrm{C}$ incubators. Recently, commercial real-time multiplex assays have been developed as screening tool for direct detection of carbapenemase genes in rectal swab (19-22). Here, we evaluated the performance of the qPCR Amplidiag ${ }^{\circledR}$ CarbaR+VRE with the automated Amplidiag $^{\circledR}$ Easy platform. The most obvious advantage of qPCR over culture is the reduced time-to-results to define the patient's carbapenemase status as compared to culture-based 
methods. In addition, the staff training requirements were minimal because specific competence in molecular biology was unnecessary. The training period for the technical staff was one day, including a description of the Amplidiag® Easy instrument, the software and handling.

In the present study, the $\mathrm{qPCR}$ Amplidiag ${ }^{\circledR}$ CarbaR+VRE assay demonstrated excellent sensitivity and NPV values (100\%) and a specificity value close to $100 \%$. In contrast, the PPV value was lower as reported in many studies performing molecular methods $(13,21,23)$. Here, almost $30 \%$ of carbapenemase-positive results by qPCR were not confirmed by selective culture. The confirmation of the presence of carbapenemase genes by simplex PCR and DNA sequencing in most of the 24 false-positives suggested that these false-positives could be actually true-positives. A first explanation of this high number of false-positive results could be a better sensitivity of qPCR than culture. In the present study, this could be due to the direct plating of rectal swab on chromogenic media without preenrichment in broth which increases the rate of detection of MDR bacteria from rectal swabs $(24,25)$. We did not deliberately perform this enrichment step in order to be close to our routine conditions for the screening rectal swabs. Indeed, enrichment of culture entails a greater amount of work and thereby is not suited for the processing of weekly 450 rectal swabs. Moreover, this step delays individual culture results by one day which might be a disadvantage in the wards where patients are preemptively isolated with enhanced precaution contact measures.

Second explanation could be that, some variants of carbapenemases may be only detectable by qPCR and not on ChromID® CARBA SMART medium. As an example, variants OXA-244 (an OXA-48 variant with a low carbapenemase activity) does not grow well on the ChromID ${ }^{\circledR}$ CARBA SMART medium that we routinely use, whereas it can be detected by the PCR Amplidiag ${ }^{\circledR}$ CarbaR+VRE (26). It is therefore not excluded that a 
number of false-positives OXA-48 may be related to the presence of this variant. A third explanation could be that the high rate of false positives may also result from the detection of carbapenemase genes present in other bacterial species from the transient digestive flora such as Shewanella spp., which has been accounted for the spread of OXA-48 in Enterobacteriaceae, or VIM and IMP- producing $P$. aeruginosa or $P$. putida $(27,28)$. The subsequent negative simplex PCR results in 7 of the 24 qPCR false-positives may result from sample degradation during freezing or laboratory errors. However, it should be noted that all these samples except two, yielded a low signal ( $\mathrm{Ct}$ ranged from 40 to 44 ) and could be misclassified with the manufacturer's $\mathrm{Ct}$ value of $<45$. Studies conducted with automated qPCR have shown that decreasing the $\mathrm{Ct}$ value below that manufacturer's value is more suitable to reduce misclassification (false positive and false negative) (13). Oueslati et al. (16), used a Ct cut-off value of $\leq 35$ by using the Amplidiag ${ }^{\circledR}$ CarbaR+VRE assay on bacterial colonies. Here, the PPV slightly increased without compromising the sensitivity with a higher $\mathrm{Ct}$ value $(\leq 42)$. However, the selection of this cut-off value cannot be recommended because it has been set based on our local hospital epidemiology. Further studies are needed to assess the performance of Amplidiag ${ }^{\circledR}$ assay due to differences in prevalence of different types of carbapenemases in hospitals and geographical regions. In particular, the performance of the Amplidiag $^{\circledR}$ CarbaR+VRE assay should be evaluated in settings with high prevalence of carbapenemase-producing non-fermenters.

Due to the high sensitivity and NPV values of qPCR, negative results can accurately rule out the presence of a colonizing CP-GNB on the day of admission. On the other hand, the PPV value $<90 \%$ did not allow patients to be clearly identified as positive CP-GNB carriers when qPCR was positive. The use of a molecular method alone seems unsuitable to define a positive patient in a low-prevalence area and therefore to implement recommended costly hygiene measures (isolation in single-bed room with designated nursing staff, staff 
reinforcement and sometimes interruption of admissions) (7, 29, 30). Some authors have proposed to consider qPCR-positive and culture negative patients as negative CP-GNB carriers, thus maintaining only standard contact precautions and continue to monitor these patients with subsequent rectal swabs (15). Another alternative would be to consider these patients as suspect CP-GNB carriers, thus maintaining or implementing contact precautions and systematically inoculate on chromogenic agar plates qPCR positive samples. Since results of the qPCR is available on the day the swab is received, plating can be done on the same day without delay. Thus, following plating, either the culture is positive and the patient is therefore definitely considered as a true positive, or the culture is negative and the patient remains under standard contact precautions until the next rectal sampling. With this algorithm and due to the low prevalence of CPEs in our hospital $(<5 \%)$, the number of swabs plated would decrease in our laboratory and therefore so would the cost and the technical time. The small price difference observed between culture-based method and Amplidiag ${ }^{\circledR}$ assay $(\sim 2 €)$ could be compensated by the reduction of time to results and therefore by the reduction of duration of additional contact precautions among patients preemptively isolated.

Finally, a combination of qPCR and culture of all qPCR positive samples may be the ideal workflow especially during cross-sectional screening of contact patients connected with

a CP-GNB case-positive patient. Indeed, qPCR provides faster time-to-results and culture of continuous surveillance of carbapenemases epidemiology is required because the sensitivity of Amplidiag ${ }^{\circledR}$ CarbaR+VRE assay may decrease if allelic variations within target genes occur or if some new or rarer carbapenemases become more prevalent in institutions.

Funding: PCR Kits were provided free of charge by Mobidiag, Finland. 
313 The funder did not contributed with the design of the study analyzing and interpreting the

314 results nor with the decision to submit the work for publication. The authors declare no other

315 conflicts of interest 


\section{References}

317 1. Nordmann P, Poirel L.2014. The difficult-to-control spread of carbapenemase 318 producers among Enterobacteriaceae worldwide. Clin Microbiol Infect 20:821-30. doi: $319 \quad 10.1111 / 1469-0691.12719$.

2. Potron A, Poirel L, Nordmann P. 2015. Emerging broad-spectrum resistance in Pseudomonas aeruginosa and Acinetobacter baumannii: Mechanisms and epidemiology.Int J Antimicrob Agents 45:568-85. doi: 10.1016/j.ijantimicag.2015.03.001.

323 3. Falagas ME, Tansarli GS, Karageorgopoulos DE, Vardakas KZ. 2014. Deaths attributable 324 to carbapenem-resistant Enterobacteriaceae infections. Emerg Infect Dis 20:1170-5. doi: 10.3201/eid2007.121004.

4. Grundmann H, Glasner C, Albiger B, Aanensen DM, Tomlinson CT, Andrasević AT, DM, Nordmann P, Poirel L, Rossolini GM, Seifert H, Vatopoulos A, Walsh T, Woodford N,

Monnet D and the European Survey of Carbapenemase-Producing Enterobacteriaceae (EuSCAPE) Working Group. 2017. Occurrence of carbapenemase-producing Klebsiella pneumoniae and Escherichia coli in the European survey of carbapenemase-producing Enterobacteriaceae (EuSCAPE): a prospective, multinational study. Lancet Infect Dis 17:153163. doi: 10.1016/S1473-3099(16)30257-2.

334 5. Dortet L, Cuzon G, Ponties V, Nordmann P. 2017. Trends in carbapenemase-producing Enterobacteriaceae, France, 2012 to 2014. Euro Surveill 22. pii: 30461. doi: 10.2807/15607917.ES22.6.30461.

6. Wilson AP, Livermore DM, Otter JA, Warren RE, Jenks P, Enoch DA, Newsholme W, 338 Oppenheim B, Leanord A, McNulty C, Tanner G, Bennett S, Cann M, Bostock J, Collins E, 339 Peckitt S, Ritchie L, Fry C, Hawkey P. 2016. Prevention and control of multi-drug-resistant 
Gram-negative bacteria: recommendations from a Joint Working Party. J Hosp Infect 92 Suppl 1:S1-44. doi: 10.1016/j.jhin.2015.08.007.

342 7. Tacconelli E, Cataldo MA, Dancer SJ, De Angelis G, Falcone M, Frank U, Kahlmeter G, 343 Pan A, Petrosillo N, Rodríguez-Baño J, Singh N, Venditti M, Yokoe DS, Cookson B; European 344 Society of Clinical Microbiology. 2014. ESCMID guidelines for the management of the 345 infection control measures to reduce transmission of multidrug-resistant Gram-negative bacteria 346 in hospitalized patients. Clin Microbiol Infect 20 Suppl 1:1-55. doi: 10.1111/1469-0691.12427.

347 8. Haut Conseil de Santé Publique. 2013. Prévention de la transmission croisée des 348 Bactéries Hautement Résistantes aux antibiotiques émergentes (BHRe). 349 http://www.hcsp.fr/explore.cgi/avisrapportsdomaine?clefr=372.

350 9. Girlich D, Anglade C, Zambardi G, Nordmann P. 2013. Comparative evaluation of a 351 novel chromogenic medium (chromID OXA-48) for detection of OXA-48 producing 352 Enterobacteriaceae. Diagn Microbiol Infect Dis 77:296-300. doi: 10.1016/j.diagmicrobio. $353 \quad 08.015$

354 10. Wilkinson KM, Winstanley TG, Lanyon C, Cummings SP, Raza MW, Perry JD. 2012. 355 Comparison of four chromogenic culture media for carbapenemase-producing 356 Enterobacteriaceae. J Clin Microbiol 50:3102-4. doi: 10.1128/JCM.01613-12.

357 11. Vrioni G, Daniil I, Voulgari E, Ranellou K, Koumaki V, Ghirardi S, Kimouli M, 358 Zambardi G, Tsakris A. 2012. Comparative evaluation of a prototype chromogenic medium 359 (ChromID CARBA) for detecting carbapenemase-producing Enterobacteriaceae in surveillance 360 rectal swabs. J Clin Microbiol 50:1841-6. doi: 10.1128/JCM.06848-11.

361 12. García-Fernández S, Hernández-García M, Valverde A, Ruiz-Garbajosa P, Morosini MI, 362 Cantón R. 2017. CHROMagar mSuperCARBA performance in carbapenem-resistant 363 Enterobacteriaceae isolates characterized at molecular level and routine surveillance rectal swab specimens. Diagn Microbiol Infect Dis 87:207-209. doi: 10.1016/j.diagmicrobio.2016.11.014. 
13. Lau AF, Fahle GA, Kemp MA, Jassem AN, Dekker JP, Frank KM. 2015. Clinical

Performance of Check-Direct CPE, a Multiplex PCR for Direct Detection of bla(KPC), bla(NDM) and/or bla(VIM), and bla(OXA)-48 from Perirectal Swabs. J Clin Microbiol 53:372937. doi: 10.1128/JCM.01921-15.

14. Lee TD, Adie K, McNabb A, Purych D, Mannan K, Azana R, Ng C, Tang P, Hoang LM. 2015. Rapid Detection of KPC, NDM, and OXA-48-Like Carbapenemases by Real-Time PCR from Rectal Swab Surveillance Samples. J Clin Microbiol 53:2731-3. doi: 10.1128/JCM.0123715.

15. Hoyos-Mallecot Y, Ouzani S, Dortet L, Fortineau N, Naas T. 2017. Performance of the $\mathrm{Xpert}^{\circledR}$ Carba-R v2 in the daily workflow of a hygiene unit in a country with a low prevalence of carbapenemase-producing Enterobacteriaceae. Int J Antimicrob Agents 49:774-777. doi: 10.1016/j.ijantimicag.2017.01.025.

377 16. Oueslati S, Girlich D, Dortet L, Naas T. 2018. Evaluation of the Amplidiag CarbaR+VRE Kit for Accurate Detection of Carbapenemase-Producing Bacteria. J Clin Microbiol 22 pii: e01092-17. doi: 10.1128/JCM.01092-17.

17. Girlich D, Bernabeu S, Grosperrin V, Langlois I, Begasse C, Arangia N, Creton E, Cotellon G, Sauvadet A, Dortet L, Naas T. 2019. Evaluation of the Amplidiag CarbaR+MCR Kit for Accurate Detection of Carbapenemase-Producing and Colistin-Resistant Bacteria. J Clin Microbiol. 57(3). pii: e01800-18. doi: 10.1128/JCM.01800-18.

18. Youden WJ. 1950. Index for rating diagnostic tests. Cancer 3:32-5.

19. Huang TD, Bogaerts P, Ghilani E, Heinrichs A, Gavage P, Roisin S, Willems E, Verbruggen AM, Francart H, Denis O, Senterre JM, Glupczynski Y. 2015. Multicentre evaluation of the Check-Direct CPE® assay for direct screening of carbapenemase-producing Enterobacteriaceae from rectal swabs. J Antimicrob Chemother 70:1669-73. doi: 10.1093/jac/dkv009. 
20. Moore NM, Cantón R, Carretto E, Peterson LR, Sautter RL, Traczewski MM; Carba-R Study Team. 2017. Rapid Identification of Five Classes of Carbapenem Resistance Genes Directly from Rectal Swabs by Use of the Xpert Carba-R Assay. J Clin Microbiol 55:2268-2275. doi: 10.1128/JCM.00137-17.

21. Souverein D, Euser SM, van der Reijden WA, Herpers BL, Kluytmans J, Rossen JWA, Den Boer JW. 2017. Clinical sensitivity and specificity of the Check-Points Check-Direct ESBL Screen for BD MAX, a real-time PCR for direct ESBL detection from rectal swabs. J Antimicrob Chemother 72:2512-2518. doi: 10.1093/jac/dkx189.

22. Traczewski MM, Carretto E, Canton R, Moore NM; Carba-R Study Team. 2018. Multicenter Evaluation of the Xpert Carba-R Assay for Detection of Carbapenemase Genes in Gram-Negative Isolates. J Clin Microbiol 56. pii: e00272-18. doi: 10.1128/JCM.00272-18

23. Tenover FC, Canton R, Kop J, Chan R, Ryan J, Weir F, Ruiz-Garbajosa P, LaBombardi V, Persing DH. 2013. Detection of colonization by carbapenemase-producing Gram-negative Bacilli in patients by use of the Xpert MDRO assay. J Clin Microbiol 51:3780-7. doi: 10.1128/JCM.01092-13.

24. Murk JL, Heddema ER, Hess DL, Bogaards JA, Vandenbroucke-Grauls CM, DebetsOssenkopp YJ. 2009. Enrichment broth improved detection of extended-spectrum-betalactamase-producing bacteria in throat and rectal surveillance cultures of samples from patients in intensive care units. J Clin Microbiol. 47:1885-7. doi: 10.1128/JCM.01406-08.

25. Jazmati N, Jazmati T, Hamprecht A. 2017 . Importance of pre-enrichment for detection of third-generation cephalosporin-resistant Enterobacteriaceae (3GCREB) from rectal swabs. Eur J Clin Microbiol Infect Dis. 36:1847-1851. doi: 10.1007/s10096-017-3000-1.

26. Hoyos-Mallecot Y, Naas T, Bonnin RA, Patino R, Glaser P, Fortineau N, Dortet L. 2017. OXA-244-Producing Escherichia coli Isolates, a Challenge for Clinical Microbiology Laboratories. Antimicrob Agents Chemother 61 pii: e00818-17. doi: 10.1128/AAC.00818-17. 
415 27. Poirel L, Bonnin RA, Nordmann P. 2012. Genetic features of the widespread plasmid 416 coding for the carbapenemase OXA-48. Antimicrob Agents Chemother 56:559-62. doi: 417 10.1128/AAC.05289-11.

418 28. Hong JS, Yoon EJ, Song W, Seo YB, Shin S, Park MJ, Jeong SH, Lee K. 2018. 419 Molecular Characterization of Pseudomonas putida Group Isolates Carrying blavim-2 420 Disseminated in a University Hospital in Korea. Microb Drug Resist 24:627-634. doi: $421 \quad 10.1089 / \mathrm{mdr} .2017 .0257$.

422 29. Birgand G, Leroy C, Nerome S, Luong Nguyen LB, Lolom I, Armand-Lefevre L, Ciotti 423 C, Lecorre B, Marcade G, Fihman V, Nicolas-Chanoine MH, Pelat C, Perozziello A, Fantin B, 424 Yazdanpanah Y, Ricard JD, Lucet JC. 2016. Costs associated with implementation of a strict 425 policy for controlling spread of highly resistant microorganisms in France. BMJ Open 426 29:e009029. doi: 10.1136/bmjopen-2015-009029.

427 30. Otter JA, Burgess P, Davies F, Mookerjee S, Singleton J, Gilchrist M, Parsons D, 428 Brannigan ET, Robotham J, Holmes AH. 2017. Counting the cost of an outbreak of 429 carbapenemase-producing Enterobacteriaceae: an economic evaluation from a hospital 430 perspective. Clin Microbiol Infect 23:188-196. doi: 10.1016/j.cmi.2016.10.005. 
Table 1 the current panel of gene targets detected by the Amplidiag ${ }^{\circledR}$ CarbaR+VRE assay

\begin{tabular}{|l|c|}
\hline \multicolumn{1}{|c|}{ Target group of genes } & Reported results \\
\hline $\begin{array}{l}\text { OXA-48 and OXA-48 like: OXA-48, OXA-162, OXA-181, OXA-204, } \\
\text { OXA-232, OXA-244, OXA-245, OXA-405 }\end{array}$ & OXA-48/181 \\
\hline KPC-1 to KPC-24 & KPC \\
\hline NDM-1 to NDM-16 & VIM \\
\hline VIM-1 to VIM-21, VIM-23 to VIM-46 & IMP \\
\hline $\begin{array}{l}\text { IMP-1 to IMP-35, IMP-37, IMP-38, IMP-40 to IMP-45, IMP-47, IMP- } \\
\text { 48, IMP-51, IMP-53 }\end{array}$ & \\
\hline Oxacillinase from Acinetobacter: & \\
\hline - OXA-23 and OXA-23 like: OXA-23, OXA-27, OXA-49, OXA-73, \\
OXA-102, OXA-103, OXA-105, OXA-133, OXA-134, OXA-146, \\
OXA-165, through OXA-171, OXA-225, OXA-239 & \\
\hline - OXA-24/40 and OXA-24/40 like: OXA-24, through OXA-26, OXA- \\
40, OXA-72, OXA-139, OXA-160, OXA-207
\end{tabular}



culture

\section{Carbapenemase types (no) Species(no)}

OXA-48 (42) Escherichia coli (9)

439

440

441

442

443

444

445

446

447

448

KPC (10)

K. pneumoniae (10)
Klebsiella pneumoniae (5)

Enterobacter cloacae (4)

Citrobacter freundii (3)

Klebsiella oxytoca (2)

E. coli+K. pneumoniae (5)

E. coli + K. oxytoca (1)

K. pneumoniae + E. cloacae (3)

K. pneumoniae $+K$. oxytoca $(3)$

$K$. pneumoniae $+C$. freundii (2)

$K$. oxytoca $+C$. freundii (2)

E. coli + E. cloacae (1)

E. coli + C. freundii (1)

K. oxytoca + E. cloacae (1)

medium 
452 Table 3 Diagnostic performance of the Amplidiag ${ }^{\circledR}$ CarbaR+VRE assay as routine screening 453 tool for direct

454 detection

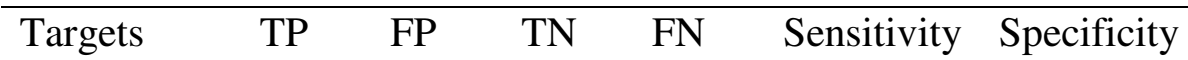

of $\mathrm{CP}-$

455 GNB in

\begin{tabular}{lllllll}
\hline OXA-48 & 42 & 13 & 1775 & 0 & 100 & 99.3
\end{tabular}
rectal

456 swabs

45

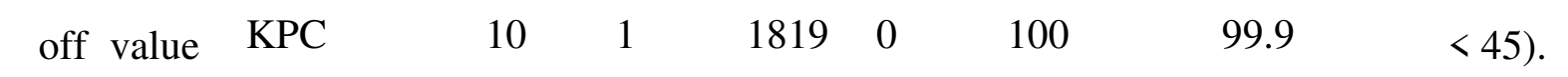

458

NDM

63

$\begin{array}{lll}1821 & 0 & 100\end{array}$

99.8

459

VIM

4

5

$1821 \quad 0$

100

99.7

IMP

$\begin{array}{llll}0 & 2 & 1828 & 0\end{array}$

99.9

460

461

462

463

464 


$\begin{array}{lllllll}\text { OXA } a b & 8 & 0 & 1822 & 0 & 100 & 100\end{array}$


Table 4 Discrepant results analysis and final interpretation using modified Ct value of $\leq 42$.

\begin{tabular}{|c|c|c|c|c|c|c|c|}
\hline \multirow[b]{2}{*}{ Samples } & \multicolumn{3}{|c|}{ Target identified by } & \multicolumn{4}{|l|}{ Discrepant analysis } \\
\hline & $\begin{array}{l}\text { reference- } \\
\text { culture method }\end{array}$ & $\begin{array}{l}\text { Amplidiag® } \\
\text { CarbaR+VRE }\end{array}$ & $\begin{array}{l}\mathrm{Ct} \text { value of } \\
\text { positive signal }\end{array}$ & $\begin{array}{l}\text { Simplex PCR plus } \\
\text { DNA sequencing }\end{array}$ & $\begin{array}{l}\text { Final } \\
\text { interpretation }\end{array}$ & $\begin{array}{l}\text { Past history of } \\
\text { CPE carriers }\end{array}$ & $\begin{array}{l}\text { CPE outbreak } \\
\text { in ward }\end{array}$ \\
\hline 1 & None & NDM & 33 & NDM & True positive & No & No \\
\hline 2 & None & NDM & 32 & NDM & True positive & Yes & OXA-48/181 \\
\hline 3 & None & NDM & 37 & NDM & True positive & No & No \\
\hline 4 & None & OXA-48/181 & 32 & OXA-48/181 & True positive & Yes & OXA-48/181 \\
\hline 7 & None & OXA-48/181 & 40 & OXA-48/181 & True positive & No & No \\
\hline 8 & None & OXA-48/181 & 42 & OXA-48/181 & True positive & No & OXA-48/181 \\
\hline 9 & None & OXA-48/181 & 42 & OXA-48/181 & True positive & No & OXA-48/181 \\
\hline 10 & None & OXA-48/181 & 37 & OXA-48/181 & True positive & No & OXA-48/181 \\
\hline 11 & None & OXA-48/181 & 40 & OXA-48/181 & True positive & No & No \\
\hline 16 & None & VIM & 29 & VIM & True positive & No & No \\
\hline 17 & None & VIM & 30 & VIM & True positive & No & No \\
\hline 18 & None & IMP & 40 & No target gene & False positive & No & OXA-48/181 \\
\hline 19 & None & IMP & 43 & No target gene & False positive & No & OXA-48/181 \\
\hline 20 & None & $\mathrm{KPC}$ & 36 & No target gene & False positive & No & No \\
\hline 21 & None & OXA-48/181 & 42 & No target gene & False positive & No & OXA-48/181 \\
\hline 22 & None & OXA-48/181 & 44 & No target gene & False positive & No & OXA-48/181 \\
\hline 23 & None & OXA-48/181 & 44 & No target gene & False positive & No & OXA-48/181 \\
\hline 24 & None & VIM & 38 & No target gene & False positive & No & OXA-48/181 \\
\hline
\end{tabular}




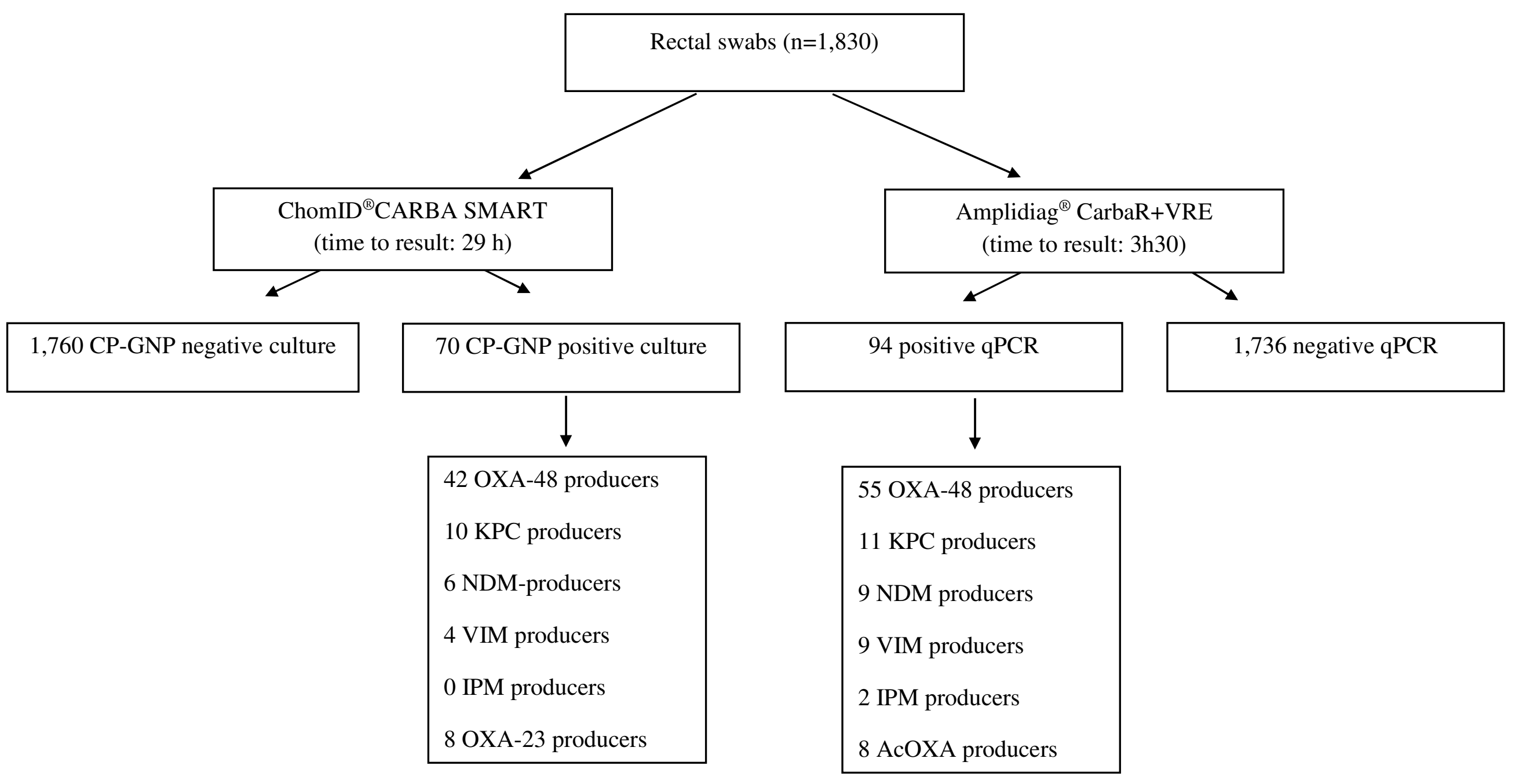

Figure 1. Results of CP-GNB culture and qPCR Amplidiag ${ }^{\circledR}$ CarbaR+VRE assay for 1830 rectal swabs screened between November 2017 and February 2018. 